\title{
Novos rumos da Filosofia Juridica
}

\author{
Pinto Ferreira \\ (Catedratico de Direito Constitucional \\ na Faculdade de Direito do Recife)
}

Os problemas fundamentais do pensamento, que sempre subjazem à base das meditações ideologicas, somente podem ser devidamente situados e resolvidos mediante uma interpretação filosofica humanista e cultural. Não é de hoje, aliás, que se salienta esse condicionamento ontologico das ideologias e a sua valoração critica adequada pelo pensamento cientifico e fillosofico, que a sociologia epistemologica e a molderna teoria do conhecimento têm destacado.

A propria filosofia renovadora de Bergson, em "Les Deux Sources de la Morale et de la Religion" mostra a contento as bases historico-sociais e biologicas da religião e da moral. De fato, o ilustre filosofo neolatino vê na propria sociedade uma das fontes da religião e da moral, no que relembra Durkheim e Levy-Bruhl, complementando, porem, que há ainda uma outra base nos referidos processos culturais, naquele élan vital de aperfeiçoamento gradativo e constante superação espiritual do homem.

Existe, realmente, em todas as atividades humanas, um condicionamento historico-social e biologico, a "Seinsverbundenheit des Wissens" aludida pelo prof. Manheim em sua "Wissenssoziologie", desde a religião à economia, e provavelmente é esta a visão desenvolvida recentemente na filosofia do direito, na sociologia, e no direito publico pelo prof. Miguel Reale. 
O prof. Miguel Reale, catedratico de Filosofia do Direito da Faculdade de Direito da Universidade de São Paulo, onde ingressou após um concurso excepcional, é o autor de diversos trabalhos de incontestavel merito, especialmente os "Fundamentos do Direito" e "Teoria do Direito e do Estado". Precisamente nos "Fundamentos do Direito" ele lançou as bases de uma nova interpretação filosofica do direito, procurando "fundar uma teoria realista do direito sobre as bases de um humanismo cultural", cuja doutrina e exposição geral foi mais tarde sintetizada pelo seu colega de diretoria do Instituto Brasileiro de Filosofia, em São Paulo, Renato Czerna.

De antemão, o prof. Miguel Reale, com uma grande capacidade de sintese reveladora de solida e ampla formação cientifica, propõe-se em sua tese a conceder uma visão panoramica das variadas tendencias da filosofia juridicas contemporanea, ou bem assim da filosofia social do diretito. Indaga com fino espirito critico as correntes de interpretação da "escola sociologica francesa" (Durkheim, Davy, Levy-Bruhl) a teoria da solidariedade social de Duguit, a posição de Jellinek e Petrajitsky, a escola do direito puro de Hans Kelsen, o idealismo axiologico de Muench e Lask, a filosiofia dos valores e da cultura de Windelband e Rickert, o relativismo de Radbruch, a doutrina etica de Max Scheler, e demais.

O prof. Miguel Reale situa-se, entre nỏs, como um representante autorizado e original do realismo culturalista. Destarte, refuta em sua magistral obra, não só a apreciação unilateral dos que vêem no direito um fenomeno puramente social, mas tambem a interpretação do direito como simples norma ideal.

Nesse sentido, adota uma posição antiformalista, rejeitando o dualismo estabelecido por Kant na "Kritik der Reinen Vernunft" entre o mundo do ser e do dever sêr, divulgado recentemente por KeIsen em sua "Allgemeine Stastslehre"。 
Verdade seja que os idealistas da Escola de Baden, com Windelband e Rickert, e à cuja doutrina se prendem mais remotamente Lask, Muench e Ravá, souberam intercalar uma terceira categoria entre o ser e o dever ser, qual seja, a cultura. Sobretudo Emilio Lask, em sua "Recthsphilosophie", e Fritz Muench, os vendadeiros fundadores da concepção culturalista do direito, abrem margem a uma interpretação mais consentanea da realidade juridica.

A filosofia do direito desenvolvida pelo professor brasileiro é um aperfeiçoamento desse culturalismo, ao qual concede uma base social, humana e cristã. Di-lo com sagacidade: "uma compreensão mais exata da natureza a dos fundamentos do Direito resultou do fato de nos termos colocado em uma posição de realismo critico, entre a unilateral preferencia dos juristas sociologos pelo fato e a unilateralidade dos juristas tecnicos seduzidos pela norma"

Daí uma nova sintese dialetica na analise do direto, conforme declara: "O Direito, em verdade, só piode ser compreendido como sintese do ser e de dever-ser. E' uma realidade bidimensional de substrato sociologico e de forma tecnico-juridica".

De passagem, cabe aliás salientar que a nova filosofia culturalista do prof. Miguel Reale tem, entre nós, pontos de contacto (afora outros de divergencia) com o pensamento juridico-filosofico de Tobias Barreto, o famoso fundador da Escola de Recife, que foi um dos precursores geniais do culturalismo contemporaneo.

Tobias Barreto não foi um pensador que passou com a sua epoca e o seu tempo. Imortalizou-se na filosofia do direito, e juntamente com Silvio Romero, Clovis Bevilacqua e Martins Junior, procedeu a uma verdadeira revolução ideologica na sociedade brasileira, criando uma escola de idéias, a que se prende o seu nome.

Ainda recentemente o prof. Gilberto Freire mostrou em sua "Sociologia" como o pensamento social de Silvio 
Romero já antecipava profundamento o sistema sociologico de Hans Freyer, ou ainda o de Max Weber. O mesmo se diria de Tobias Barreto que, antes de Lask e Muench, lançou o esboço inicial de uma filósofia culturalista do direíto.

Senão vejamos. Declara o prof. Gilberto Freire a respeito de Silvio Romero: "Silvio Romero, porem, andou tão proximo de concepcões atuais da sociologia cientifica, inclusive da ciencia hibrida que procuramos, nestas paginas, opor à dos bio-sociologos e à dos naturalistas absolutos, tanto quanto à dos culturalistas puros, que não hesitamos um instante em reconhecer um precursor brasileiro, embora vago e nada coerente, da concepção de sociologia aqui esboçada..." E dizia então Silvio Romero, com palavras surpreendentes: "A verdadeira escola do direito, da moral, da estetica, da critica, da sociologia, da atividade humana, em suma, será aquela que reunir os fatores da natureza e os da civilização, os fatores fisiologicos e os psicologicos, os biologicos e os sociais".

O talento incontestavel de Silvio Romero se revela, assim, como o de um notavel precursor das teorias da sociologia e do direito contemporaneos, conforme reconhecem criticos insuspeitos, numa antecipação às novissimas escolas de pensamento. Daí a sua frase que vem mesmo a proposito, quando, em sua "Historia da Literatura Brasileira", se fereria às escolas literarias: "Eu não sou classico e nem romantico e nem parnasiano; não estou com a velha nem com a nova geração... quero estar com a novissima, com aquela que ainda há de vir".

Essa mesma antecipação teve ensejos de realizar-se com Tobias Barreto, quando, em sua prova escrita de concurso à Faculdade de Direito do Recife, em 1822, o famoso teutosergipano assim prefigurava: "Bem como as artes, bem como as ciencias, o direito é um produto da cultura humana. Fora desta, em qualquer grau que ela seja, nenhum direito, nenhuma disciplina das forças sociais". 
Essa visão culturalista, aliás, coincide com o nosso pensamento desenvolvido na tese. "Da Soberania", e com ela se mostra a contento que, na tradicional Faculdade de Direito do Recife, as tendencias ideologicas dominantes, sejam nos meios universitarios, sejam no professorado, mais se inclinam para uma visão humanista e cultural. E o que demonstrou ultimamente o prof. Djacir Meneses, quando em um trabalho ex-professo com o titulo "A Influencia de Tobias Barreto na Conceituação Filosofica do Direito de Clovis Bevilaqua", salientou devidamente a orientação culturalista subjacente na doutrina do velho Tobias.

Entretanto, retornando a uma apreciação critica sobre a obra filosofica de Miguel Reale, parece-nos divisar as fontes do seu pensamento nas especulações de Max Scheler, em "Der Formalismus in der Ethik und die Materielle Werthenethik"; de Bergson, na sua exposição classica sobre as bases da religião e da moral; ou ainda dos neokantianos da Escola de Baden ou sul-ocidental alemã (Suedwestdeustche Schule) chefiada por Windelband e Rickert, e integrada por Emil Lask, Bauch, Kroner, Hoeniswald e outros.

Realmente, o jurista-filosofo brasileiro acentua nitidamente a "influencia exercida pelo intuicionismo de Bergson sobre a filosofia contemporânea", para aduzir a seguinte consideração: “A filosofia de Bergson conjuga-se hoje, na doutrina de alguns juristas, com as idéias de um dos mais notaveis pensadores de nosso tempo, Max Scheler, cujas teorias nos parecem, mais fecundas no plano do direito que o biologismo etico do autor de Les Deux Sources de la Morale et de la Religion".

Poder-se-ia mesmo consultar o ensaio do prof. Glaucio Veiga sobre "A Sociologia do Saber de Max Scheler", mostrando como na referida filosofia o ideal e o real se interpenetram e são concorrentes na formação de uma coltura, tese aprovada evidentemente pelas especulações de filosofia juridica do prof. Miguel Reale. 
E' inconteste, porem, que o ilustre pensador nacional, possuidor de uma densa e variada cultura juridica, filosofica e sociologica, supera as idéias dominantes na doutrina de Scheler, Lask e Muench, com a sua doutrina original e fecunda do realismo culturalista.

Entretanto, o realismo culturalista não se limita a uma investigação teorica das verdades, mas tambem não se furta a um élan pratico de reforma social, economica e espiritual da sociedade, cujos lineamentos estão bosquejados em um outro importante estudo de Miguel Reale, na sua "Teoria do Direito e do Estado".

Adota, então, di-lo habilmente, "uma posição de justo equilibrio, a que se prende a doutrina culturalista do Estado e do Direito", destacando porem a sua divergencia diante da "concepção cultural dos neo-idealistas" (Lask e Muench), com a aceitação do culturalismo realista.

O Estado é uma realidade cultural, sobre a qual ministro uma analise magistral, que tambem encaminha para a interpretação da soberania e da democracia. Na verdade, a sua filosofia culturalistas é dum teor liberal e democratico social, na defesa intransigente dos postulados liberais da cultura moderna.

O Estado, segundo o mestre da Faculdade de Direito de São Paulo, "é uma pessoa juridica destinada a realizar o bem comum, o conjunto das condições sociais de uma vida plenamente humana; não pode deixar de ver o homem senão como uma pessoa dotada de liberdade, numa autolimitação dos poderes estatais em beneficio da liberdade".

Convem, ademais, salientar uma linha ideologica semelhante entre o pensamento do prof. Miguel Reale e o nosso, cujas bases foram recentemente divulgadas no prefacio à 2. ${ }^{\text {a }}$ edição do livro "Principios Gerais do Direito Constitucional Moderno", talvez devido à comum influencia de Tobias Barreto e de seu culturalísmo filtrada através do "Sistema de Ciencia Positiva do Direito", do prof. Pontes de Miranda. 
A Estado moderno é um Estado de Direito, que se caractcriza pela limitação do seu poder, naquilo que, entre nós, Pontes de Miranda chamou de "principio sociologico da diminuição do quantum despotico", ou mais simplesmente, de humanização progressiva do poder, como declaram Bertrand Russell e Wiesser.

Diminui na historia o grau de despotismo e violencia, em proveito da legalidade e do direito, e uma tal tendencia à jurisdicidade consagra a tecnica do Estado moderno.

Por derradeiro, acresce formular entre o sistema de idéias que desenvolvemos e a concepção de vida de Miguel Reale, uma certa divergencia, posto que o nosso realismo culturalista tem um conteudo socialista, é um realismo cultural e socialista. Trata-se naturalmente de um socialismo moderno e constitucional, de conteudo humanista e cientifico, como ocorre com Laski e Attlee, porem intensamente ligado ao drama das massas populares e ì luta pratica pelas suas reivindicações minimas

O proprio Clovis Bevilaqua, um dos luminares da Escola do Recife, em um dos seus maravilhosos trabalhos, já aludia genialmente às leis da evolução juridica no seguinte esquema: "expansão crescente da personalidade, socialização progressiva dos poderes juridicos, alargamento da equidade e saturação mais forte da moral".

Enfim, a renomado jurista-filosofo brasileiro coroa a sua doutrina com os postulados de uma filosofia cristã, focalizando a harmonia do Estado e da liberdade, "na plenitude dos valores essenciais ao progresso de uma cultura cristã". Como bem se está vendo, talvez aqui se encontré o mesmo élan de um cristianismo cultural, imanente na obra de Bergson, e a que não seria de todo indiferente o espirito do filosofo nacional.

Portanto, o prof. Miguel Reale, talentoso jurista-filosofo brasileiro, nivela-se com as mais autenticas vocações dà sistematica juridica nacional, como Pontes de Miranda, 
Djacir Meneses, Silvio Romero, Clovis Bevilaqua, Mario Lins, trazendo uma contribuição valiosa à teoria do Direito e do Estado. A sua capacidade construtiva e o seu sentido de originalidade, o estilo plastico e acessivel, a linguagem sobria e simples, e a vastidão de seus conhecimentos, colocam-no na posição de um dos grandes professores universitarios do pais, a quem muito deve e de quem muito se honra a cultura nacional. 